\title{
Religious Conservatives and Safe Sex: Reconciliation by Nonpublic Reason
}

ROBERT S. TAYLOR

\begin{abstract}
Religious conservatives in the United States have frequently opposed public health measures designed to combat sexually transmitted diseases among minors, such as sex education, condom distribution, and human papillomavirus (HPV) vaccination. Using Rawls's method of conjecture, I will clear up what I take to be a misunderstanding on the part of religious conservatives: even if we grant their premises regarding the nature and source of sexual norms, the wide-ranging authority of parents to enforce these norms against their minor children, and the potential sexual disinhibition effects of the above public health measures, their opposition to at least one of these measures, HPV vaccination, cannot be justified. In fact, their comprehensive doctrines, when properly interpreted, should lead them to back this measure and thereby draw closer to a policy consensus with other citizens regarding teenage sexual health.
\end{abstract}

In "The Idea of Public Reason Revisited," John Rawls discusses three kinds of nonpublic reason that serve as auxiliaries to public reason itself: declaration, conjecture, and witnessing. He defines the second of these, conjecture, as follows:

We argue from what we believe, or conjecture, are other people's basic doctrines, religious or secular, and try to show them that, despite what they might think, they can still endorse a reasonable political conception that can provide a basis for public reasons. The ideal of public reason is thereby strengthened. However, it is important that conjecture be sincere

Robert S. Taylor is associate professor of political science, 469 Kerr Hall, University of California, Davis, 1 Shields Ave., Davis, California 95616 (rstaylor@ucdavis.edu).

I thank Robert P. George, Ben Highton, Yuch Kono, Michael Lamb, David McCourt, Stephanie Mudge, Ryan Reed, Michelle Schwarze, the participants at the May 2012 Policy Watch Seminar at the University of California, Davis, Institute of Governmental Affairs, and the editor and six reviewers at American Political Thought for their helpful comments and suggestions.

American Political Thought: A Journal of Ideas, Institutions, and Culture, vol. 3 (Fall 2014).

2161-1580/2014/0302-0006\$10.00. @ 2014 by The Jack Miller Center. All rights reserved. 
and not manipulative. We must openly explain our intentions and state that we do not assert the premises from which we argue, but that we proceed as we do to clear up what we take to be a misunderstanding on others' part, and perhaps on ours. (Rawls 1999, 594-95)

As an example of such conjecture, Rawls earlier suggests that a religious doctrine may endorse toleration in the belief that "such are the limits God sets on our liberty": that is, he speculates that a spiritual creed (e.g., the "free faith" doctrine of Locke's A Letter Concerning Toleration) may back liberty of conscience on the grounds that "only faith and inward sincerity gain our salvation and acceptance with God" and therefore coercion in matters of religious belief is inappropriate or even impious (Rawls 1993, 145 n. 12; 1999, 59091). Rawls reasons here not as a religious believer himself but as a scholar speculating about how a certain kind of religious believer might justify a main element of liberal democratic regimes, liberty of conscience, from within their own comprehensive doctrine.

Rawls's remarks about conjecture are brief, however, and raise a number of unanswered questions about its methods, limits, and potential risks. In a recent article, Micah Schwartzman (2012) takes on the valuable task of trying to answer such questions. He identifies three key aspects of reasoning by conjecture. First, he notes that conjecture is "a form of reasoning. It is not simply an attempt at rhetorical persuasion. The idea is to present people with arguments that give them good reasons, as evaluated from within their own comprehensive views, for endorsing a reasonable political conception" (Schwartzman 2012, 6). In order for this endorsement to be stable, reasoning should also be grounded on moral rather than strategic considerations; in other words, it should aspire to principled agreement, not mere modus vivendi. Second, conjecturers "offer arguments based on premises they do not accept. They argue from within comprehensive doctrines, other than their own, for the purpose of justifying a reasonable political conception"; we are obligated to reveal this to those whose comprehensive doctrines we engage, both to assure them of our sincerity and to get them to "take our arguments seriously, on the ground that these arguments are based on premises to which we believe they are committed" (8). Third, conjecture "need not be based on arguments that are merely tentative or suggestive. ... Conjecturers may be quite certain that their claims are conclusively justified on the basis of particular comprehensive doctrines," though the degree of certainty will obviously be a function of their knowledge of the doctrines in question, their skill and sensitivity as conjecturers, and so on (8).

Schwartzman then considers three corresponding objections-dangers of conjecture that we as practitioners must try to avoid. First, those whose doc- 
trines we engage may be suspicious of our intentions: they may question our sincerity and worry that we are manipulating them. To minimize this danger, Schwartzman argues that we must adopt a "principle of full disclosure. It says that reasoning from conjecture is sincere and non-manipulative if, and only if, conjecturers (i) disclose that they do not believe the premises from which they argue, and (ii) disclose whether they believe their arguments are justifiable from within the comprehensive views of their intended audience" (Schwartzman 2012, 11). Second, conjectural "criticisms made by outsiders are often perceived, and rejected, as forms of cultural imperialism" (19). Schwartzman acknowledges that this might give us reason to refrain from conjecture, but if adherents of certain doctrines fail to ratify reasonable political conceptions and internal critics are silent (or silenced), external critics may have a civic duty to engage in conjecture to defend these conceptions. Third, adherents of these doctrines may question the epistemic authority of conjecturers because they "have not been trained to read texts correctly, to draw on relevant analogies and metaphors, to reference apposite commentaries and interpretations, and, more generally, to frame moral arguments in terms acceptable within [these] traditions" (20). Conjecturers can respond by becoming experts on these doctrines or, alternatively, by conceding their inexperience but noting that, as outsiders, they might be in a better position to identify doctrinal flaws invisible to adherents because of overfamiliarity, groupthink, insularity, and so on. ${ }^{1}$

These aspects and dangers of the conjectural method have been on full display in recent work on the relationship between Islam and political liberalism. Scholars such as Andrew March (2009), Lucas Swaine (2009), and Nicholas Tampio (2012) have produced groundbreaking research that asks whether observant Muslims can endorse the political principles of pluralistic liberal democracies and the wider international order (also see Schwartzman 2012, 14-19). These scholars skillfully use conjecture to demonstrate that Islam and liberal democracy can indeed be reconciled and that Muslims can consequently participate in an overlapping consensus with their non-Muslim fellow citizens without having to abandon or even seriously compromise their religious beliefs. As powerful, compelling, and vital as this work has been in the wake of 9/11 and the Arab Spring, it may not be the best vehicle for exemplifying the conjectural method. Conjecture in this heated context seems

1. March (2009) offers a distinct but intersecting presentation of the methods and dangers of conjecture, especially in chap. 2 ("Methods: The Ethics of Comparative Ethics"). On the importance of sincerity and full disclosure, see 70-71; on avoiding charges of cultural imperialism, see 57-64; and on the problem of epistemic authority, esp. in cases of religious comprehensive doctrines, see 66-67 (the "religious integrity objection"). 
especially likely to draw charges of cultural imperialism, even if the outside intervention is carried out in good faith and is crucial for the defense of political liberalism, as it certainly is in this case. Moreover, problems of epistemic authority are likely to arise, not because the scholars in question have failed to acquire expertise in Islamic thought (they plainly have, especially in the case of March), but rather because most of their target audience of Anglophone political theorists lacks the doctrinal expertise to evaluate their conjectural arguments.

This article tries to reduce (but not eliminate) these dangers of conjecture by looking at a different example of reconciliation by nonpublic reason: persuading US religious conservatives to ratify reasonable public health measures to fight sexually transmitted diseases (STDs) among minors, such as sex education, condom distribution, and human papillomavirus (HPV) vaccination. $^{2}$ They have offered a variety of reasons for opposing these measures, including the illegitimacy of state encroachment upon parental prerogatives and a fear that such measures may unintentionally encourage teenage sex by reducing its health risks. My general sense is that their critics-like the critics of political Islam-consider their opposition to be a sign of political backwardness and think that it calls into question not simply the reasonableness of their religious beliefs but perhaps even their fitness to participate in a liberal democratic political order.

Against these critics, I will contend here that religious conservatives' beliefs are, at least in this area, entirely reasonable-but that they are not what religious conservatives believe them to be. Using conjectural methods, I will clear up what I take to be a misunderstanding on the part of religious conservatives: even if we grant their premises about the nature and source of sexual norms, the wide-ranging authority of parents to enforce these norms against their minor children, and the potential sexual disinhibition effects of these public health measures, their opposition to at least one of these measures,

2. I take religious conservatism (also referred to as the Christian or Religious Right) to be a socially conservative US political movement, composed mostly of evangelicals and Catholics, whose members apply their religious beliefs to matters of politics and public policy, especially with regard to abortion, homosexuality, pornography, school prayer, and sex education. Its leaders include Gary Bauer, James Dobson, and Tony Perkins, and two of its most prominent organizations are Focus on the Family and the Family Research Council, which were founded by Dobson. Former Republican presidential candidates Michelle Bachmann, Mike Huckabee, and Rick Santorum are closely associated with it. For an overview, see Wilcox and Robinson (2011, 8-13). Foremost among its intellectual luminaries is the Princeton professor and natural law theorist Robert P. George, who has become increasingly active in US politics; his seminal scholarly works are Making Men Moral: Civil Liberties and Public Morality (1993) and In Defense of Natural Law (1999). I will refer at times to these organizations, figures, and works over the course of the article. 
HPV vaccination, cannot be justified. In fact, their comprehensive doctrines, when properly interpreted, should lead them to back this measure and thereby draw closer to a policy consensus with other citizens regarding teenage sexual health.

I will proceed as follows. After giving key medical and political background information on HPV vaccination, I will look at the three major religiousconservative arguments against this policy (involving issues of vaccine safety, state encroachment upon parental authority, and the potential sexual disinhibition effect) and propose that only the third can plausibly justify their opposition. Next, I will lay out in greater detail the three premises listed above, accepting them for the sake of argument but showing they cannot ground opposition to the policy in question, at least if religious conservatives have reasonable ideas about acceptable enforcement mechanisms for sexual norms. Finally, I will defend my conjectural argument against two powerful objections and explore why religious conservatives have not noticed this problem with their policy views.

Before starting this task, however, I would like to express the hope that my article, by serving as a kind of "proof of concept" for domestic deployment of the conjectural method, will encourage greater use of conjecture by academics and other public intellectuals in the United States. It has become a commonplace to bemoan political polarization in this country, whether it is understood as merely an elite phenomenon or as reflective of growing divisions in the electorate. ${ }^{3}$ One possible reaction to such ideological divergence is for political opponents to begin to view each other as irreconcilable enemies and to regard democratic politics as simply war by other means. Another, more aspirational response is for opponents to try to seek common ground, not by compromises that may unravel with political power shifts because they fail to engage the deeper commitments of the participants, but instead by arguments based on premises that one's opponents can accept. These efforts will often, perhaps even ordinarily, be unable to stay within the antiseptic bounds of public reason: they will require us to understand, argue within, and even delicately reconstruct the comprehensive doctrines of those with whom we disagree. If done poorly, such efforts will merely provoke resentment, charges of arrogance, and perhaps even further polarization. If done well, they hold out the promise of reconciliation by nonpublic reason. My article is intended as a modest attempt to achieve such reconciliation in one critical corner of the public policy realm.

3. For opposing views on this issue, see Fiorina (2011) and Abramowitz (2010). 


\section{MANDATORY HPV VACCINATION FOR PRETEEN GIRLS: THE MEDICAL AND POLITICAL BACKGROUND}

HPV is the most common STD in the United States, infecting at least half of all sexually active people at some point in their lives. It is generally asymptomatic, with the immune system successfully fighting it off. In some cases, though, the virus persists and can produce cancer. HPV causes almost all cervical cancer (approximately 12,000 cases per year in the United States, of which one-third are fatal); it has also been linked to several other cancers. Two HPV vaccines are licensed by the Food and Drug Administration and recommended for 11- and 12-year-old girls by the Centers for Disease Control, the American Cancer Society, and the American Academy of Pediatrics, among others: Cervarix (made by GlaxoSmithKline) and Gardasil (made by Merck), which are administered in three shots over 6 months at a cost of about \$400. These vaccines are both safe and effective: an August 2011 report of the Institute of Medicine of the National Academies found them to be safe (though it noted that they might on rare occasions cause anaphylaxis, a severe allergic reaction), and both are very effective at preventing infections of HPV types 16 and 18, two high-risk HPVs that cause about $70 \%$ of all cervical cancers. Both Virginia and the District of Columbia require the vaccination as a condition of school attendance, and a host of other states provide funding for or public education about the vaccines. ${ }^{4}$

Compulsory HPV vaccination grabbed headlines 3 years ago after the September 12, 2011, Republican presidential debate, in which Representative Michelle Bachmann and former Senator Rick Santorum criticized Governor Rick Perry of Texas for having signed an executive order in 2007 (later overturned by the legislature) mandating vaccination for all sixth-grade girls (Gabriel and Grady 2011). Apart from Bachmann's “crony-capitalism” charge, which stemmed from the fact that Perry's former chief of staff was a lobbyist for Merck, their complaints mostly echoed long-standing religiousconservative concerns regarding vaccine safety, state encroachment upon parental authority, and the potential sexual disinhibition effect (Gibbs 2006; MacLaggan 2007; Grady 2011). As I indicated above, worries about vaccine safety are largely baseless: apart from rare allergic reactions, the vaccines cause no substantial side effects, and there is no scientific evidence of a connection

4. This information is from the Centers for Disease Control (2014a). I will assume that the vaccine is cost effective, i.e., that its benefits (in terms of cancer prevention) outweigh its costs (in terms of both its price and rare side effects). I will also focus exclusively on HPV's effects on women: although it can cause cancer in men (which has led the CDC to recommend vaccinating boys as well), the health risks are much greater for women. 
between the vaccines and autism (Grady 2011). ${ }^{5}$ Objections to state assumption of parental prerogatives, on the other hand, are not so easy to dismiss: parents in the United States, at least, have broad authority to make healthcare decisions for their minor children, so intrusion into this realm ought to be justified by a compelling state interest (e.g., the need to prevent the spread of communicable diseases). However, all state governments already require a (varying) panoply of immunizations for school attendance, usually including HepB (hepatitis B), DTaP (diphtheria, tetanus, and pertussis), and MMR (measles, mumps, rubella [Dare 1998, 126-27]). ${ }^{6}$ Religious conservatives, in contrast to libertarians, have rarely objected to these extensive, comprehensive programs of compulsory immunization. Why is the HPV vaccine any different? Linda Klepacki, an analyst for sexual health at Focus on the Family, offers this explanation: "This is a disease you don't catch by sneezing or coughing. It's linked to behavior. You don't contract HPV by sitting in the classroom. So this is a different issue" (quoted in Gibbs 2006). ${ }^{7}$ But this is also true of other diseases covered by these required vaccination programs (e.g., tetanus [in DTaP]), coverage that religious conservatives have never opposed, which again raises the question of what makes HPV special.

The answer, of course, is that HPV is transmitted sexually, and religious conservatives worry that by reducing the health risk of sex, HPV immunization will unintentionally encourage premarital sex and even promiscuity among minors. For example, Bridget Maher, a former policy analyst with the Family Research Council, warns that "giving the HPV vaccine to young women could be potentially harmful, because they may see it as a license to engage in premarital sex"; Reginald Finger, a former medical advisor to Focus on the Family, is concerned that "if people begin to market the value of the vaccine or tout the vaccine that this makes adolescent sex safer, then that would undermine the abstinence-only message" (quoted in Gibbs 2006). The technical term for such an effect is "behavioral disinhibition," defined by the $\mathrm{CDC}$ as "an increase in unsafe behaviors in response to perceptions of safety caused by the introduction of a preventive or therapeutic intervention" (Gibbs 2006). The best study to date on the sexual disinhibition effects of HPV vaccination on preteen girls found no evidence for such disinhibition (Bednarczyk et al. 2012). This was a retrospective cohort study, however, rather than a randomized controlled trial (the most trusted variety of clinical study), which

5. The vaccine/autism myth has its roots in Wakefield et al. (1998), a fraudulent article later retracted by the Lancet.

6. For recommended immunization schedules and state mandates, see the Centers for Disease Control (2014b); on the justification for overriding parental authority in these cases, see Dawson $(2005,202)$.

7. More systematic evidence for such beliefs among religious conservatives is offered by Schuler et al. (2011). 
raises concerns about selection bias and spurious causality: because these girls were not randomly assigned to treatment and control groups, but rather selfselected (i.e., parent-selected) into the HPV vaccination treatment, it is harder to draw inferences about the causal relationship between vaccination and sexual activity. For example, it could be the case that the parents who chose vaccination for their preteen girls were also more likely to educate their girls about the health risks of sex and the advantages of postponing sexual activity; if so, this may have masked any disinhibiting effects of the vaccination itself.

Moreover, disinhibition effects have been found in associated policy contexts, including sexual ones. For example, a recent study of preexposure prophylaxis (PREP)—a relatively new approach to HIV prevention that involves daily administration of an antiretroviral therapy as a protective measure against infection-found that $35 \%$ of the gay men surveyed would be less likely to use condoms if they were put on PREP (Golub 2010). There is a sizable literature in economics on disinhibition as well, though it is often referred to there as "offsetting" behavior. Sam Peltzman published the seminal piece in this literature, which showed that the presence of seat belts in cars caused drivers to drive more recklessly, thereby increasing the risk of injury to pedestrians and partially wiping out the safety gains achieved by seat belts. Subsequent studies largely confirmed Peltzman's surprising finding (Peltzman 1975; Crandall and Graham 1984). Consequently, I believe we cannot rule out the possibility that a modest degree of sexual disinhibition may result from HPV vaccination.

Such potential sexual disinhibition should cause all citizens concern, be they religious or nonreligious. As the HIV example in the previous paragraph illustrates, sexual disinhibition may expose individuals to further health risks (e.g., catching other STDs), offsetting to some degree the advantages brought by a sexual health intervention and therefore affecting our assessment of its net benefits. ${ }^{8}$ As noted above, the best study to date found no evidence of disinhibition from HPV vaccination and therefore no evidence of such offsetting effects, but were better studies to find such effects, they might reasonably influence citizen support for vaccination.

Beyond this general reason for concern about sexual disinhibition, religious conservatives have an additional, special reason for concern, one that is focused not on the health consequences of disinhibited sexuality but rather on

8. In rare cases, offsetting can be so extreme that a public health intervention generates net losses. E.g., one study finds that a 1972 Food and Drug Administration regulation mandating child-resistant bottle caps on aspirin and other drugs may have led to an increase in analgesic poisonings of children due to various offsetting behaviors, such as parents' incorrectly assuming that these products were child safe enough to be kept on lower shelves (Viscusi 1984). 
the disinhibited sexuality itself. They consider this kind of sexuality to be such a grave moral wrong that, as we have seen, they even object to a vaccination program that runs some risk of encouraging it. Given their views on teenage sexuality, religious conservatives are understandably worried about disinhibition. In the next section, however, I will argue that such anxiety cannot justify their opposition to mandatory HPV vaccination.

\section{THE RELIGIOUS-CONSERVATIVE CASE FOR MANDATORY HPV VACCINATION}

Three premises jointly underwrite religious-conservative opposition to compulsory HPV vaccination, namely:

1. Sexual norms, which are products of God's legislative will (as revealed by natural reason, scripture, prophecy, etc.), absolutely condemn premarital sex and especially promiscuity.

2. Parents should have broad authority to enforce sexual norms against their minor children.

3. HPV vaccination might unintentionally increase sex among minors by lowering its health risks (sexual disinhibition). ${ }^{9}$

Starting from these premises, religious conservatives argue against mandatory HPV vaccination in the following way: parents are under a strong religious obligation to keep their minor children from having sex, but mandatory vaccination undermines their enforcement efforts through sexual disinhibition, threatening both their children's chastity and their authority as parents; therefore, it is morally wrong. I will show below that this argument cannot be sustained, because it implicitly ascribes an enforcement power to parents that most religious conservatives would reject.

Before doing so, however, I must pause to say two things. First, my conjectures here are minimalist in nature: when I reconstruct the religiousconservative case against HPV vaccination (which has not received a previous philosophical treatment of which I am aware), critique it, and anticipate their objections to this critique, I try to make as few assumptions about their religious beliefs as possible. For example, I do not specify in premise 1 precisely how they come to learn of these sexual norms, as they may disagree among

9. Regarding premises one and two, see George (1999, chaps. 9, 10, and 16) and George and Moschella (2011). The voluntarist phrasing of premise one ("products of God's legislative will"), though consistent with the views of the evangelicals who constitute the bulk of the Religious Right, might be rejected by some Catholics, including George. Rephrasing it in a rationalist fashion would not significantly alter the nature or conclusions of this section's argument, however. 
themselves about it. My interventions in their comprehensive doctrines go no further than is necessary to make my argument regarding HPV vaccination. Doing otherwise would invite charges of (sub)cultural imperialism and raise doubts about my epistemic authority; these are likely to happen anyway, but a minimal intervention will at least diminish these inevitable risks of conjecture.

Second, consistent with Schwartzman's principle of full disclosure (which I discussed in the introduction), I should now state that I do not accept the first premise about either the nature or the source of sexual norms, but I do believe that parents should possess the described broad authority and that HPV vaccination might have sexual disinhibition effects. I will later make use of providential/design arguments and scripture and should therefore also state that I do not find physico-theological claims persuasive (though I am swayed by Kant's ethico-theology) and that while I am instructed and moved by certain biblical passages (e.g., John 8:1-11), I do not think the Bible has any special moral authority. Last, I believe the argument I am about to present is justifiable from within the comprehensive doctrines of religious conservatives: in other words, its premises, deductions, and conclusions are consistent with and even follow from their doctrines, though they will ultimately have to be the judge of this.

To see what is wrong with the religious-conservative argument against HPV vaccination, consider the following series of hypothetical questions that might be asked of the religious-conservative parent of a preteen daughter:

1. Suppose you had a magic wand that, when waved over your daughter, would afflict her with cervical cancer. Would it be morally acceptable to use this wand to enforce sexual morality? For the vast majority of religious conservatives, it surely would not be. ${ }^{10}$

2. Now consider a somewhat different enforcement mechanism: upon detection of sexual immorality, she would be required to spin a roulette wheel; if the ball fell into a certain range of numbered pockets, the

10. Admittedly, I am speculating here on the basis of personal experience (I grew up among religious conservatives in East Tennessee and have several in my family), and I recognize that some religious conservatives might believe that parents possess a power of life and death over their offspring - not an unlimited one, necessarily, but rather one that might legitimately be employed to enforce important (sexual) norms and parental authority more broadly. There is certainly a scriptural basis for such a belief (Deuteronomy 21:18-21; cf. Exodus 21:17, Leviticus 20:9, and Matthew 15:4), and parental "honor killings" of daughters due to perceived sexual transgressions are commonly in the news. I would contend, however, that this belief is a minority opinion among religious conservatives in the United States. That being said, the argument that follows will be unconvincing to those who hold this belief, and it is therefore not addressed to them. Other kinds of arguments would have to be used to sway this (hopefully tiny) minority. 
wand would be used on her; otherwise, not. Would it be morally acceptable to threaten her in this way to enforce sexual morality? Again, surely not, and presumably the answer would not depend on how large the range of pockets was.

3. Now suppose that the magic wand operated in a wholly different way: instead of causing cancer directly, it caused it indirectly and contingently. To be specific, suppose that the magic wand, when waved over your daughter, placed a microscopic "chastity machine" inside her, and that this odd machine, upon detection of sexual immorality, automatically delivered the stochastic punishment described just above (i.e., a roulette wheel inside the chastity machine would spin and, if the ball fell into a certain range of numbered pockets, it would afflict her with cervical cancer). Would it be morally acceptable to use this wand on her to enforce sexual morality? Again, surely not.

4. Now suppose that someone else-say, a morally overzealous neighbor-had used this magic wand on your daughter. Would you be morally obligated to remove the chastity machine from her if you could? Surely you would: a girl's parents are duty-bound not just to refrain from harming her but also to intervene to prevent her from being harmed.

I want to suggest that if the religious-conservative parent would answer "yes" to question 4, then he or she should support HPV vaccination, as the choice envisioned there is structurally equivalent to the vaccination decision. After all, every girl is born with such a "chastity machine" inside her: it is her innate susceptibility to the HPV virus, which is probabilistically linked to cervical cancer. To immunize a girl against HPV is to remove the machine that a morally overzealous Nature has placed within her; thus, if a parent is morally obliged to remove this machine, he or she is also obliged to immunize. Because of this moral obligation, religious conservatives cannot object to compulsory HPV vaccination (assuming its safety and efficacy): as I pointed out earlier, they do not object to the compulsory vaccination programs already run by the states, doubtless because they acknowledge a compelling state interest in preventing the spread of communicable disease, an interest that overrides parental prerogatives; if HPV vaccination in particular conflicted with their other moral commitments, mandating it might raise special problems, but as we have seen it does not-even religious conservatives are morally required to have their daughters vaccinated. ${ }^{11}$

11. Of course, if it did raise such problems, an opt-out provision for the daughters of religious conservatives would be preferable to abandoning mandatory HPV vaccinationthough perhaps not from their perspective, if they saw it as their moral duty to protect the 
A likely objection to my line of argument so far might run as follows. First, perpetrating a harm and permitting a harm are two very different things. This distinction between "doing" and "allowing" is vital to both deontological ethics and commonsense morality: as Samuel Scheffler puts it, we generally believe that "people have a greater responsibility ... for what they do than for what they merely allow or fail to prevent" (Scheffler 2004, 215). For example, most people would say that I bear less responsibility for failing to give a starving man a loaf of bread than for stealing a loaf of bread from him, even if the consequences are the same in the two cases. Hence, one might argue that religious-conservative parents bear less responsibility for leaving intact the chastity machine that Nature implanted than they would have borne had they (counterfactually) put it there themselves, even though the consequences are the same. Perhaps their responsibility is so diminished as to extinguish their duty to remove it. In other words, the usual doing/allowing asymmetry means that one can answer "no" to questions 3 and 4 without threat of inconsistency, and thus religious conservatives do not have to vaccinate their preteen daughters against HPV.

Were the parties in question all independent adults, this might be a plausible claim, but they are clearly not: the preteen daughter is a minor, lacking certain qualities of rational agency, and the parents have a special relationship with her, namely guardianship. I would contend that these dual features largely close the usual moral gap between doing and allowing, especially where (as in the present case) severe bodily harm, perhaps even death, is at stake. A preteen girl is not in a position-intellectually, financially, or in most cases legally—to protect her own health interests here; parents have a strong obligation, morally and legally, to protect them on her behalf. Failure to do so is a disgraceful dereliction of duty, unless there are extenuating circumstances (e.g., they are unaware of the dangers or unable to afford vaccination); a concern for her future chastity, though certainly reasonable, does not qualify as such a circumstance.

chastity of all of our nation's daughters. This raises an interesting question, however: should religious conservatives be able to take advantage of existing opt-out provisions in such programs? (The one in Virginia, e.g., has a very generous opt-out provision [ Wynia 2007, 3-4].) If their reason for doing so is concern about sexual disinhibition, then they should not: as we have seen, their comprehensive doctrine obliges them to vaccinate their daughters, so there is no reason the opt-out provisions should apply to them, given their motive. I will set to one side the question of whether other philosophical objections (e.g., those of libertarian parents) might justify the allocation of such a privilege. (Such allocations raise difficult enforcement problems, as with conscientious objection to military service.) In many cases, of course, the optimal rate of vaccination in a specific population is less than $100 \%$, because of the "herd-immunity" effect (Dare 1998, 136-37). If so, the privilege of not being vaccinated should be given to those with legitimate medical concerns (e.g., past allergic reactions to vaccines) or allocated by lottery. 
The narrow evaluative gap between doing and allowing in this special case-between the active placement of a chastity machine in the preteen daughter and the passive failure to remove it once there-has a disturbing implication, one that the four-question sequence above was meant to tease out: refusing to immunize your daughter against HPV in order to preserve her chastity is tantamount to threatening her with an often fatal disease as punishment for sexual immorality. I emphasize the word "tantamount" here: I am unaware of any religious conservatives who justify their position this way in public, nor do I believe that this is the way they justify their position to themselves in private-and to suggest otherwise is not just uncharitable but counterproductive. ${ }^{12}$ Religious conservatives sincerely think that when they refuse to vaccinate their daughters, they refrain from a harmful act, one that threatens their chastity, and they thereby protect them from the temptations of a sexually libertine culture. Nevertheless, my analysis indicates a near moral equivalence between creating such a susceptibility and declining to remove it when you are fully aware of the likely consequences, an equivalence resulting from the stringency of parental duties to prevent physical harm, the vulnerability of young minors, and the seriousness of the physical harm involved. To refuse to immunize in this context is effectively to claim the authority to use a dangerous disease to promote sexual morality. Religious conservatives think that parents have a broad authority to enforce sexual norms, but it is difficult to believe that, on further reflection, many of them would countenance an authority this broad, because it appears to give a power to mere mortals that should be reserved to God-or does it?

\section{ANOTHER LIKELY OBJECTION: THEODICY}

Question 4 above is ambiguous on one point: the identity of the "someone else" who uses the magic wand on the religious-conservative's daughter. If he or she were a malicious person or even a morally overzealous one, like the neighbor, the religious conservative's answer would likely be "yes." But what if the "someone else" were God? Disease, after all, is part of God's providential order, and He must therefore have intended that Nature put these chastity machines in girls at birth. ${ }^{13}$ To knowingly thwart His will here would

12. The National Organization for Women, in an earlier round of this debate, was uncharitable in precisely this way when it suggested that religious conservative opposition to mandatory HPV vaccination "presumably relies on a fear of cancer death to promote abstinence" (quoted in Gibbs 2006).

13. I set aside the possibility that disease is not part of God's providential order because it is intentionally caused by agents outside of God's control (e.g., demons); such a possibility calls into question God's omnipotence (or perhaps omniscience) and is therefore heretical to 
be sinful; thus, the religious conservative must answer "no" to question 4 and duly oppose the HPV vaccine.

I seriously doubt that many religious conservatives would endorse such an argument, as it smacks of medieval fatalism and is inconsistent with their normal views on disease and medical intervention. Setting aside minority sects (e.g., Christian Scientists), the Abrahamic faiths do not consider medical science to be impious, and for good reason: we cannot pretend to know enough about God's plan for us to know how He intended us to respond to diseasesperhaps He meant them to be a challenge to us, things to be conquered by our God-given reason, so that a refusal to combat them would itself be irreverent. ${ }^{14}$ Regardless, why would the HPV vaccine be uniquely impious among all the other vaccines we develop and whose use religious conservatives support?

One possible answer is that, contrary to my claim above, we can sometimes read God's will off the Book of Nature, especially when a disease seems so narrowly tailored that His will is made manifest by it. HPV may be such a disease: it can only be contracted sexually, and though it might be passed to an unsuspecting spouse, it can be reliably avoided by couples who remain celibate until marriage and faithful during it; moreover, multiple sexual partners are a major risk factor for the disease. While not perfectly tailored to punish premarital sex and promiscuity, it is perhaps close enough to generate a strong suspicion among religious conservatives that God is sending us a message by it, thereby supplementing scripture's message (e.g., 1 Corinthians 7$){ }^{15}$

The problem with this refined version of the earlier argument is that HPV is not the only disease that appears designed to punish sin. For example, type 2 (adult-onset) diabetes is strongly associated with corpulence, as a widely cited review article notes: "in conjunction with genetic susceptibility . . . type 2 diabetes is brought on by environmental and behavioral factors such as overly rich nutrition, sedentary lifestyle, and obesity" (Zimmet et al. 2001, 782).

the Abrahamic religious traditions I am working within here. Also, the fact that the connection between HPV and cervical cancer is probabilistic does not necessarily imply that God is playing dice with the universe: even if God's will is not inscrutable, it may still be indistinct to our limited understanding, in which case we may describe His plan probabilistically without ascribing any randomness to God Himself.

14. Perhaps I should have said that they do not normally consider medical science to be impious. Exceptions include (for some believers) embryonic stem-cell research, cloning, advances in abortion technologies, etc. I should add that scripture offers mixed messages about medical science and its practitioners and consequently little clear guidance: cf., e.g., Mark 2:17 and Mark 5:24-34.

15. Certain religious conservatives have claimed on such grounds that AIDS is God's punishment for homosexuality. See, e.g., Johnson and Eskridge (2007), who reproduce the following quote from Falwell: "AIDS is not just God's punishment for homosexuals. It is God's punishment for the society that tolerates homosexuals." 
These behavioral risk factors, however, are merely euphemisms for two of the seven deadly sins in the Christian tradition, gluttony and sloth, which are condemned often by scripture (e.g., Proverbs 23:2, Philippians 3:19 [gluttony]; Proverbs 18:9 [sloth]). Now suppose not only that a pill existed that would cut this physiological connection between gluttony/sloth and type 2 diabetes but that someone seriously proposed that parents withhold it from their children in order to prevent behavioral disinhibition and, relatedly, impiety. ${ }^{16} \mathrm{Al}-$ most everyone-including most religious conservatives, I suspect-would consider such a proposal to be not just inhumane but unhinged. The same logic applies with equal force to HPV, however: if thwarting God's (apparent) punitive will is acceptable with respect to type 2 diabetes, why not with respect to HPV? One answer might be that the link between HPV/cervical cancer and lust (sexual sin) is tighter than the link between diabetes and gluttony/sloth, allowing us to draw more confident inferences about God's will, but this is a doubtful empirical claim; if anything, the latter connection seems stronger than the former. Another answer might be that lust is a more important sin to combat than gluttony/sloth, and we are therefore justified in thwarting God's will in the latter case but not in the former. Besides being theologically dubiousare we really entitled to second-guess God's punitive judgments? - by this very choice we would return responsibility for punishment to our own hands, thereby reengaging my arguments from the prior section: if we reclaim the power to decide which sins are punished by Nature and which not, then we, not God, are accountable for it. I therefore conclude that theodicial reasoning cannot extract religious conservatives from their moral duty to vaccinate their preteen daughters against HPV.

\section{A FINAL QUESTION}

Before moving to the conclusion, we should stop for a moment and ask why religious conservatives make the error that I have ascribed to them. After all, no one is more familiar with religious-conservative premises and arguments than they are-why wouldn't they have noticed this supposed defect in their policy views themselves? One danger of conjecture, as I have noted several times in the article, is lack of epistemic authority on the part of the conjecturer, and here I am admittedly at a disadvantage: despite some limited childhood

16. Tragically, adult-onset diabetes is becoming increasingly common among obese children, making my example all too realistic: there were approximately 3,600 new cases per year between 2002 and 2005 (Grady 2012). Incidentally, I assume here that the health benefits of such a pill would outweigh the costs, including any offsetting behavior of the kind discussed at the end of sec. 1. 
training and adult study, I have nowhere near the expertise on these doctrines that most of their adherents do, and thus in most cases they would likely be justified in ignoring my concerns. As I pointed out in the introduction, however, outsiders can on occasion notice features of religious doctrines and cultures that those on the inside fail to see because of overfamiliarity, groupthink, and insularity, and I believe that is the case here. Religious conservatives labor under a particular distorting belief that, as an outsider, I do not have, and this has permitted me to see certain flaws in their policy positions despite my admitted lack of expertise. So what distorting belief do I have in mind?

Consider first the distinction between sin and what I will call "sin enablers," that is, things that make sin more probable by rendering it less expensive or easier to access. For instance, consuming pornography is a sin, while lessening state censorship of it or making it more readily available in public libraries is a sin enabler. Religious conservatives tend to view contemporary Western culture and governance as a complex of such sin enablers, one that threatens their families and religious communities with moral corruption. They also appear to believe that in order to wage an effective war against sin, they must fight sin enablers in whatever guise they may take, from permissive pornography laws to mandatory HPV vaccination of their preteen daughters. ${ }^{17}$ This Manichaean vision blinds them to vital differences between the various kinds of sin enablers and explains their failure, I think, to see the tragic flaw in their response to the HPV vaccine.

I have no interest in challenging this general worldview here-anyone having any contact with contemporary popular culture should have at least limited sympathy for it - nor is it my business to do so, but I do want to resist its propensity to lump all sin enablers together and then demand that they be confronted in the same unyielding way. Some sin enablers, from a religiousconservative perspective, will have no compensating benefits and will consequently need to be fought without quarter. Perhaps permissive pornography laws are an example of this: whatever benefits they produce accrue not to religious conservatives but to other people (e.g., pornography consumers and creators, civil libertarians). Other sin enablers, however, will have compensating benefits for religious conservatives themselves, and this will complicate their determination of an optimal response. HPV vaccination is the latter sort of sin enabler: though it may cause sexual disinhibition, it also guards the daughters of religious conservatives against cervical cancer. As I have argued, their proper response is therefore to accede to it but also to explore ways to minimize its unintended consequences, for example, by punishing their chil-

17. To see this worldview at work with respect to pornography, see George (1999, chap. 10). 
dren more severely for sexual violations or by monitoring them more assiduously. In other words, they should respond to possible disinhibition with a reinhibiting intensification of enforcement, not with resistance to vaccination itself. In general, religious conservatives ought to work harder to identify those sin enablers with compensating benefits and respond to them more appropriately; doing so would, I suspect, moderate public policy disagreements with their fellow citizens.

\section{CONCLUSION: BROADER RECONCILIATIONS?}

If the arguments I offered above are sound, then religious conservatives should end their opposition to compulsory HPV vaccination. As the four-stage sequence of hypothetical questions revealed, refusing to immunize your daughter against HPV in order to preserve her chastity is tantamount to threatening her with an often fatal disease as punishment for sexual immorality, yet religious conservatives would surely reject this approach in parallel medical contexts (see the obesity/diabetes example in sec. 3, above). Furthermore, theodicial reasoning cannot extract them from their moral duty to immunize their preteen daughters: such reasoning would either commit them to beliefs about disease that they do not accept or lead them into a theologically dubious second-guessing of God's punitive judgments. Mandatory HPV vaccination advances a compelling state interest in checking the spread of disease, and that interest overrides parental interests in enforcing sexual norms against their children-not on secular-humanist grounds alien to religious conservatives, but instead on the basis of premises, arguments, and texts central to their own traditions and by repeated appeal to two other things with similarly deep roots in their culture: internal consistency and simple humanity.

At this point, religious-conservative readers may think my promise in the introduction to defend them against their critics was insincere: after all, I have spent the entire article trying to part them from a policy position to which some of them, at least, are strongly wedded. But the promise was an entirely serious one. After the Bachmann/Santorum attack on Perry and in earlier discussions of this issue, many criticisms of the religious-conservative position were a poisonous cocktail of incomprehension, condescension, and dismissiveness. Opponents simply refused to take religious conservatives' starting assumptions seriously, and then went on to ascribe views to them that they did not hold. ${ }^{18}$ These responses were embarrassingly counterproductive, doing

18. The nadir was probably Bill Maher (2007), who ridiculed the idea of sexual disinhibition ("it is like saying if you give a kid a tetanus shot she will want to jab rusty nails in her feet; it is like being against a cure for blindness because it will encourage masturba- 
nothing to bridge a growing divide in the American political landscape but much to widen it. In this article, I have tried to model a different kind of response, one that worked diligently and (I hope) respectfully to engage with religious conservatives on their own doctrinal territory and show that they can sometimes reach common ground with their opponents without abandoning cherished beliefs. More ambitiously, I have tried to offer a proof of concept to scholars and other public intellectuals for American deployment of the conjectural method. Were they to use it extensively and effectively, reconciliation by nonpublic reason might become a real political possibility, not just a pious hope.

\section{REFERENCES}

Abramowitz, Alan. 2010. The Disappearing Center: Engaged Citizens, Polarization, and American Democracy. New Haven, CT: Yale University Press.

Bednarczyk, Robert A., Robert Davis, Kevin Ault, Walter Orenstein, and Saad B. Omer. 2012. "Sexual Activity-Related Outcomes after Human Papillomavirus Vaccination of 11- to 12-Year-Olds." Pediatrics 130 (5): 798-805.

Centers for Disease Control. 2014a. "Human Papillomavirus (HPV)." http://www.cdc .gov/hpv.

. 2014b. "Vaccines and Immunizations." http://www.cdc.gov/vaccines.

Crandall, Robert W., and John D. Graham. 1984. "Automobile Safety Regulation and Offsetting Behavior: Some New Empirical Estimates.” American Economic Review 74 (2): 28-31.

Dare, Tim. 1998. "Mass Immunisation Programmes: Some Philosophical Issues." Bioethics 12 (2): 125-49.

Dawson, Angus. 2005. “The Determination of 'Best Interests' in Relation to Childhood Vaccines." Bioethics 19 (2): 188-205.

Fiorina, Morris, Samuel Abrams, and Jeremy Pope. 2011. Culture War? The Myth of a Polarized America. Boston: Longman.

Gabriel, Trip, and Denise Grady. 2011. "In Republican Race, a Heated Battle over the HPV Vaccine.” New York Times, September 13.

George, Robert P. 1993. Making Men Moral: Civil Liberties and Public Morality. Oxford: Clarendon.

. 1999. In Defense of Natural Law. Oxford: Clarendon.

George, Robert P., and Melissa Moschella. 2011. "Does Sex Ed Undermine Parental Rights?" New York Times, October 18.

Gibbs, Nancy. 2006. "Defusing the War over the 'Promiscuity' Vaccine." Time, June 21.

tion") and cast all Christians as enemies of science, esp. medical research: "There is only one kind of medical science that excites Christians, and that is anything that proves life begins earlier and earlier in the womb. If you could use stem cells to prove that life begins at foreplay, the pope would turn the Vatican into a lab. These people do not really want to see a cure for anything, except homosexuality." 
Golub, Sarit A., William Kowalczyk, Corina L. Weinberger, and Jeffrey T. Parsons. 2010. "Preexposure Prophylaxis and Predicted Condom Use among High-Risk Men Who Have Sex with Men." Journal of Acquired Immune Deficiency Syndromes 54 (5): 548-55.

Grady, Denise. 2011. "Remark on HPV Vaccine Could Ripple for Years.” New York Times, September 19.

—. 2012. "Obesity-Linked Diabetes in Children Resists Treatment." New York Times, April 29.

Johnson, Hans, and William Eskridge. 2007. "The Legacy of [Jerry] Falwell's Bully Pulpit." Washington Post, May 19.

MacLaggan, Corrie. 2007. "Some Lawmakers Receiving Angry Messages about Mandate Requiring Vaccinations for Girls.” Austin American-Statesman, February 6.

Maher, Bill. 2007. “Christians Crusade against Cancer Vaccine.” Salon.com, March 2. http://www.salon.com/2007/03/02/hpv_7.

March, Andrew. 2009. Islam and Liberal Citizenship: The Search for an Overlapping Consensus. New York: Oxford University Press.

Peltzman, Sam. 1975. "The Effects of Automobile Safety Regulation.” Journal of Political Economy 83 (4): 677-725.

Rawls, John. 1993. Political Liberalism. New York: Columbia University Press.

. 1999. "The Idea of Public Reason Revisited.” In Collected Papers, ed. Samuel Freeman, 573-615. Cambridge, MA: Harvard University Press.

Scheffler, Samuel. 2004. "Doing and Allowing." Ethics 114 (2): 215-39.

Schuler, Christine L., Paul L. Reiter, Jennifer S. Smith, and Noel T. Brewer. 2011. "HPV Vaccine and Behavioral Disinhibition." Sexually Transmitted Infections 87 (4): 349-53.

Schwartzman, Micah. 2012. "The Ethics of Reasoning from Conjecture." Journal of Moral Philosophy 9 (4): 1-24.

Swaine, Lucas. 2009. "Demanding Deliberation: Political Liberalism and the Inclusion of Islam." Journal of Islamic Law and Culture 11 (2): 92-110.

Tampio, Nicholas. 2012. Kantian Courage: Advancing the Enlightenment in Contemporary Political Theory. New York: Fordham University Press.

Viscusi, W. Kip. 1984. "The Lulling Effect: The Impact of Child-Resistant Packaging on Aspirin and Analgesic Ingestions.” American Economic Review 74 (2): 324 27.

Wakefield, Andrew, et al. 1998. "Ileal-Lymphoid-Nodular Hyperplasia, Non-specific Colitis, and Pervasive Developmental Disorder in Children.” Lancet 351 (9103): 637-41.

Wilcox, Clyde, and Carin Robinson. 2011. Onward Christian Soldiers? The Religious Right in American Politics. Boulder, CO: Westview.

Wynia, Matthew K. 2007. “Mandating Vaccination: What Counts as a 'Mandate' in Public Health and When Should They Be Used?" American Journal of Bioethics 7 (12): 2-6.

Zimmet, Paul, K. G. M. M. Alberti, and Jonathan Shaw. 2001. "Global and Societal Implications of the Diabetes Epidemic.” Nature 414 (6865): 782-87. 